\title{
Effect of the Grain Shape on Abrasive Tool Performance
}

\author{
Ivan Shepelev ${ }^{1, *}$, Sergey Kryukov ${ }^{1}$, and Natalya Baidakova $^{2}$ \\ ${ }^{1}$ Volzhsky Polytechnic Institute (branch) of Federal State Budget Educational Institution of Higher \\ Education Volgograd State Technical University; Engelsa St. 42a, Volzhsky, Volgograd Region, \\ 404121, the Russian Federation \\ ${ }^{2}$ Volzhsky Branch of Federal State Budget Educational Institution of Higher Education National \\ Research University Moscow Power Engineering Institute; Prospect Lenina 69, Volzhsky, Volgograd \\ Region, 404110, the Russian Federation
}

\begin{abstract}
The results of studying the effect of the grain shape on abrasive disc performance are presented. The grain shape was conveniently divided into two classes: isometric and non-isometric. The results of the microhardness tests, elastic properties tests, and mechanical strength tests of grains various in shape are given. The test results make it clear that grain microhardness slightly decreases as the grain shape changes from isometric to the plate shape. The grain elasticity also decreases. It is demonstrated that variations in the industrial grain volume and weight can be indicative not only of the changed grain size composition, chemical composition etc., but of a significant variation in the correlative content of grains different in shape. The bulk weight difference of diversiform grains is important for the structure, structural density, and matrix packing of abrasive discs. It is found that the grain shape is an essential feature that predetermines abrasive tool performance to a greater extent.
\end{abstract}

\section{Introduction}

In order to determine the nature of the grain shape influence on abrasive tool performance, it is necessary to analyze the interrelation of the shape and other grain properties. Effect of the shape on grain performance in an abrasive disc can obviously manifest itself not only directly, but in a complex interdependency with other grain properties [1-17].

\section{Materials and methods}

A vibrodynamic classifier (VDC) was used to separate the grains [1-7]. The grain shape was conveniently divided into two classes: isometric and non-isometric. Besides, particles with the aspect ratio $l / h<2$, wherein $l$ is the length and $h$ is the particle width or height, were considered as isometric. All isometric particles meeting the $l / h<2$ criterion have a

\footnotetext{
*Corresponding author: waness28@gmail.com
} 
similar shape and are solid. The non-isometric portion of the material is represented by diversiform particles: plates with notable thickness, thin plates, needles etc. (Fig. 1).

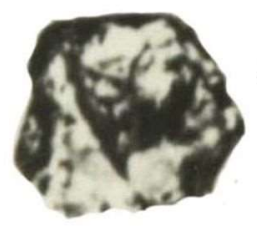

a) Isometric particle

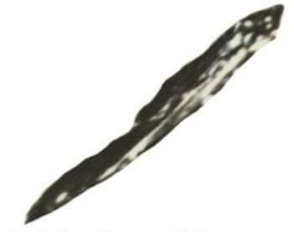

b) Needle particle

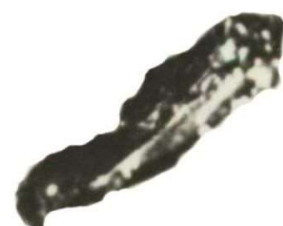

c) Non-isometric particle

Fig. 1. Particle shapes

Industrial abrasive grains feature various shapes of individual grains. Yet some persistent regularities of grain percentage with a particular shape can be found depending on the crushing method, the material etc. For example, medium-grain fractions $(200-800$ $\mu \mathrm{m})$ of white fused alumina contain $50-65 \%$ of isometric particles and fine-grain fractions $(50-160 \mu \mathrm{m})$ contain $25-45 \%$ of such particles.

The quantitative relation of grain different in shape for a variety of abrasive materials is shown in Fig. 2. The grain fineness is fraction F 20. The diagram shows that the distribution curves are distinct from each other. Besides, brown fused alumina contains more isometric grains than white fused alumina, while silicon carbide (especially green silicon carbide) contains only a little of isometric grains: almost $50 \%$ of green silicon carbide grains are represented by intermediate-shape and plate-shape grains.

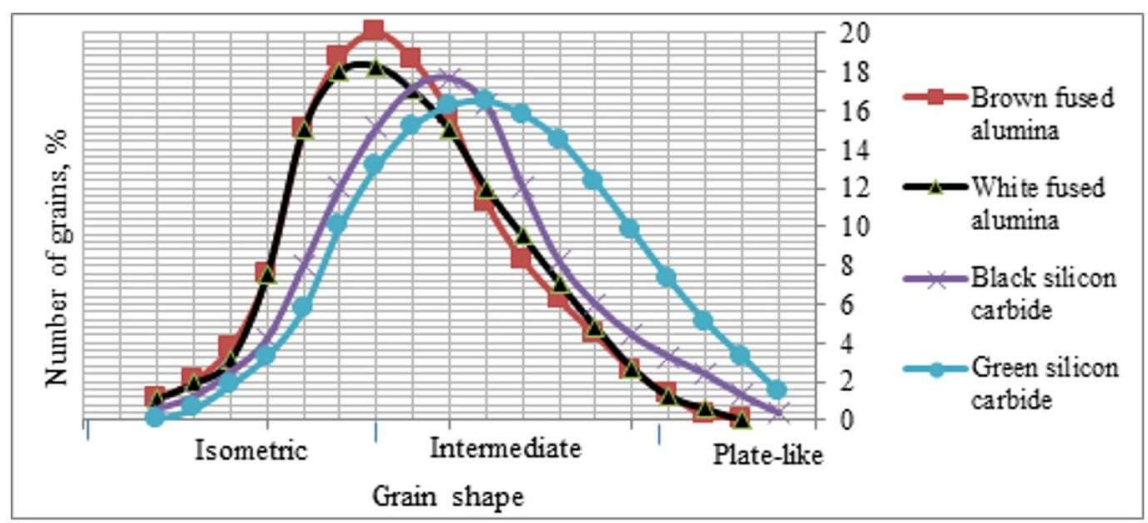

Fig. 2. Content of grains different in shape among the industrial grains of various abrasive materials.

\section{Research result}

Table 1 demonstrates the results of the microhardness tests of diversiform grains of brown fused alumina with grain size F 20 and the comparison results of the elastic properties of the same grains.

Table. 1. Microhardness and elasticity of diversiform grains.

\begin{tabular}{|l|c|c|}
\hline \multicolumn{1}{|c|}{ Grainshape } & Microhardness, $\mathrm{kg} / \mathrm{mm}^{2}$ & $\begin{array}{c}\text { Elasticity } \delta, \% \text { (in relation to } \\
\text { isometric grains) }\end{array}$ \\
\hline Isometric & 2330 & 100 \\
\hline Intermediate & 2270 & 90 \\
\hline Plate & 2080 & 80 \\
\hline
\end{tabular}


The test results make it clear that grain microhardness slightly decreases as the grain shape changes from isometric to the plate shape. The grain elasticity also decreases.

The mechanical strength is a material property determined in the process of industrial grain destruction at certain loads. According to the results of the mechanical strength analysis of grains different in shape and size (Fig. 3), such grain strength slightly changes as the grain shape varies. However, the relationship between the grain strength and shape is evident.

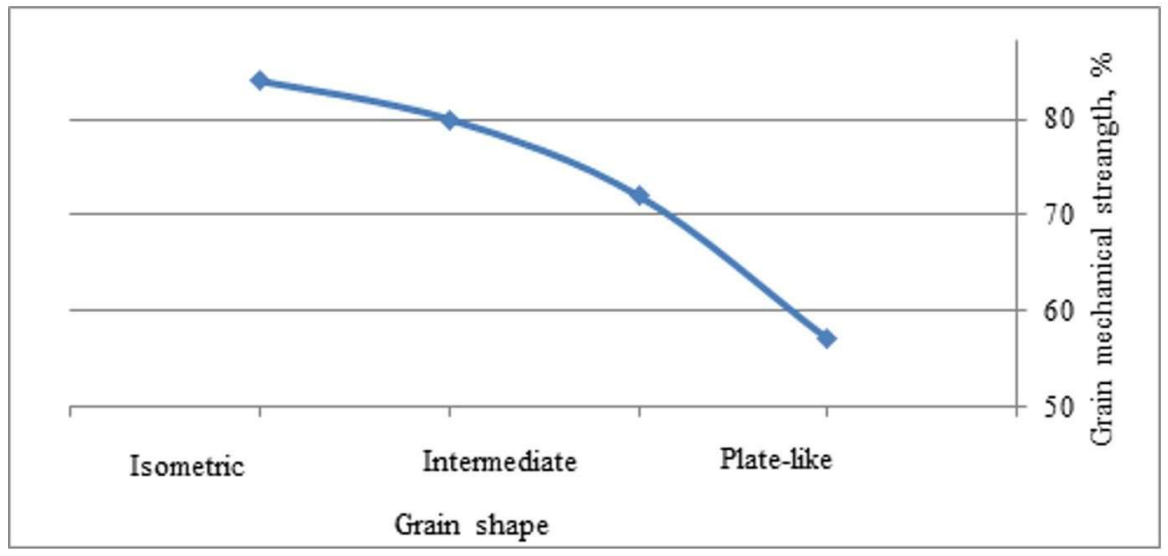

Fig. 3. Mechanical strength variations of grains different in shape and size

Considering that the content of monocrystalline and aggregate grains and the mineral composition of diversiform grains are nearly the same, the difference in their mechanical crushing strength is mainly associated with their geometry. Since bending resistance of a cubical body is higher than that of an equal plate-like body.

On the ground of comparing the data stated above, it is believed that the strength of the cutting edges of diversiform grains does not vary significantly.

Bulk weight of grains different in shape and size was also determined. Theanalysisresultsare given in Fig. 4.

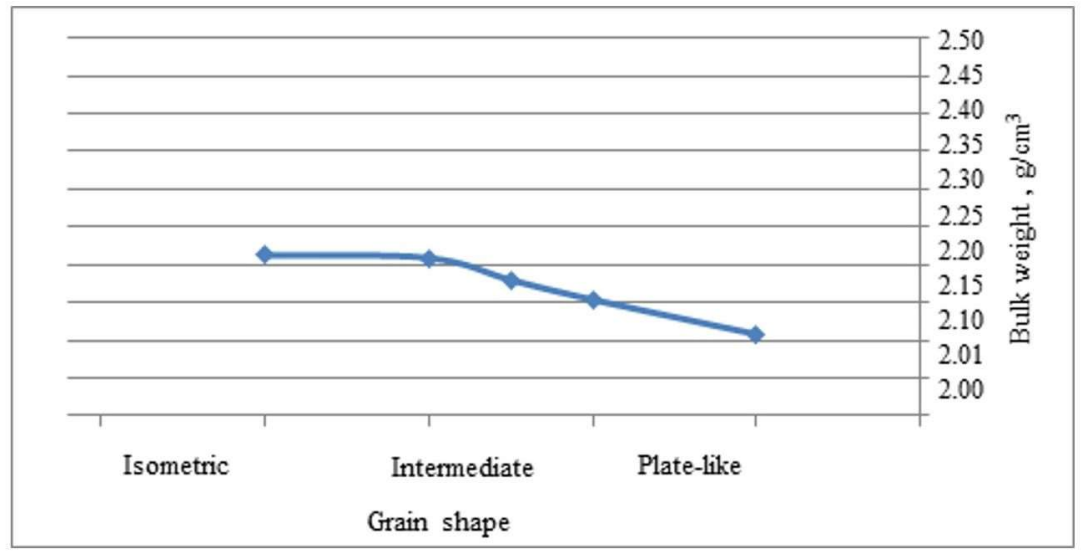

Fig. 4. Bulk weight variations of grains different in shape and size

The results demonstrate distinct dependence of the grain bulk weight on the grain shape. This suggests more close-packed arrangement of isometric grains in the tool matrix as compared to non-isometric grains. Thus, in general, variations in the industrial grain 
volume and weight can be indicative not only of the changed grain size composition, chemical composition etc., but of a significant variation in the correlative content of grains different in shape.

The bulk weight difference of diversiform grains is important for the structure, structural density, and matrix packing of abrasive discs. Besides, the grain surface area also changes as the grain shape varies (Table 2). Brown fused alumina grains with size F 20 were used for measurements.

Table. 2. Surface area of diversiform grains.

\begin{tabular}{|c|c|c|c|}
\hline Grainshape & Isometric & Intermediate & Plate \\
\hline Grain surface area, $\mathrm{mm}^{2}$ & 9.8 & 10.6 & 12.4 \\
\hline
\end{tabular}

It also requires variance in the number of bonds within a disc, in other words, it changes its structure. Besides, the grain surface area affects the cohesion strength of grains and as a consequence on the abrasive disc mechanical strength.

To check the relationship between the grain shape and size, single-grain weight, linear dimensions (particle length $l$, width $b$, height $h$ ), and average size $z=\frac{l+b+h}{3}$ of diversiform grains were measured.

The measurements were made using grains of brown fused alumina of grade E5 divided into fractions F24, F20, F16, and F10 by screenless classifying. The measurement results are shown in Fig. 5. It is demonstrated clearly that single-grain weight does not change as the shape varies. This indicates that diversiform grains of the same fraction are equivalent.

The linear measurements testified that grain length $l$ increases and height $h$ decreases as the shape changes from circular to plate-like. Grain width $b$ remains virtually constant and irrespective of the grain shape. Thus, a number of abrasive grain properties correlate to the grain shape.

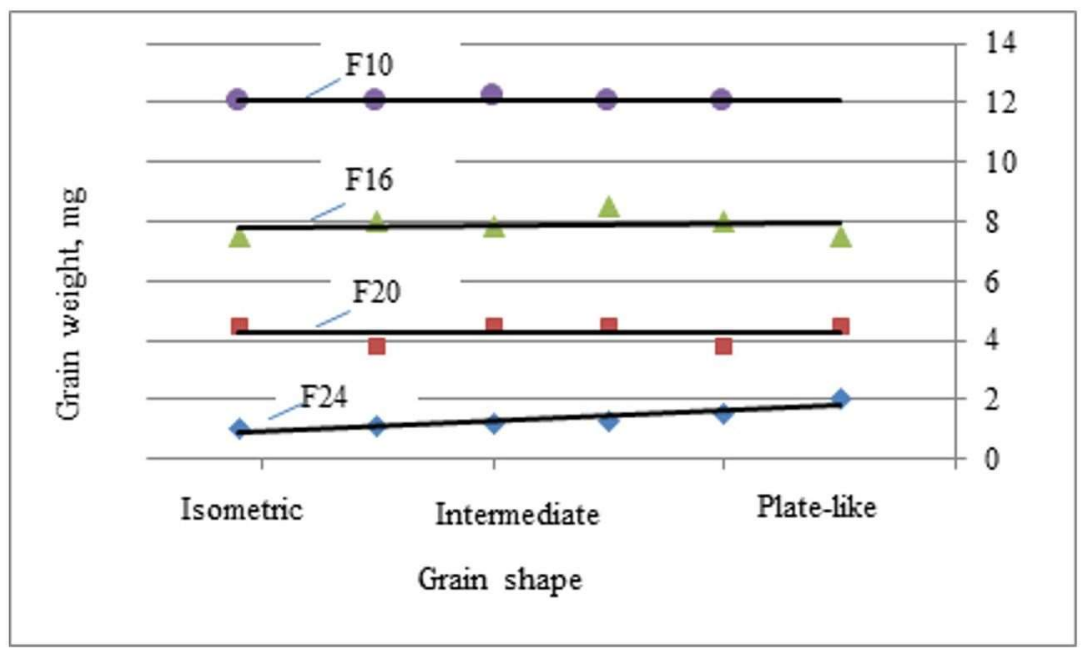

a) Grain weight 


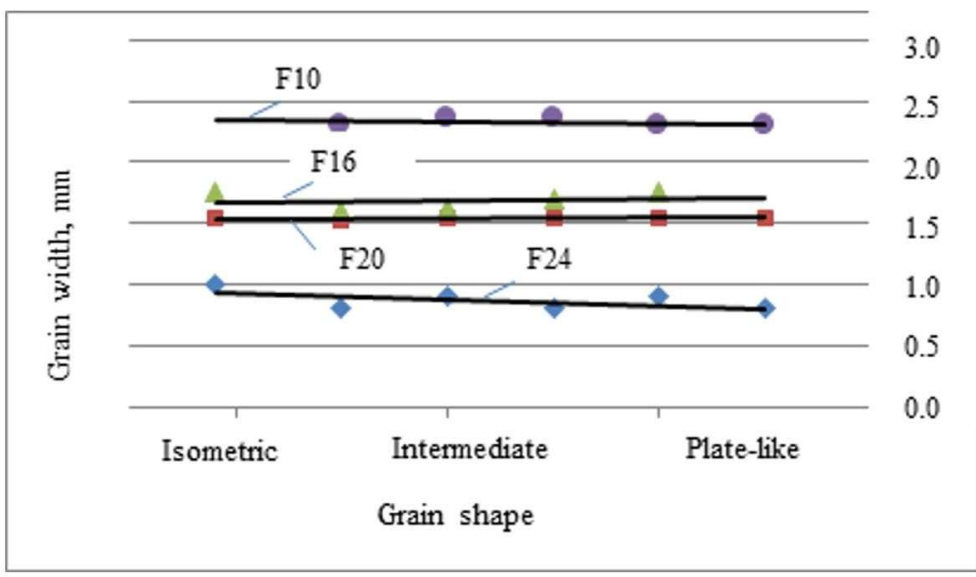

b) Grain width

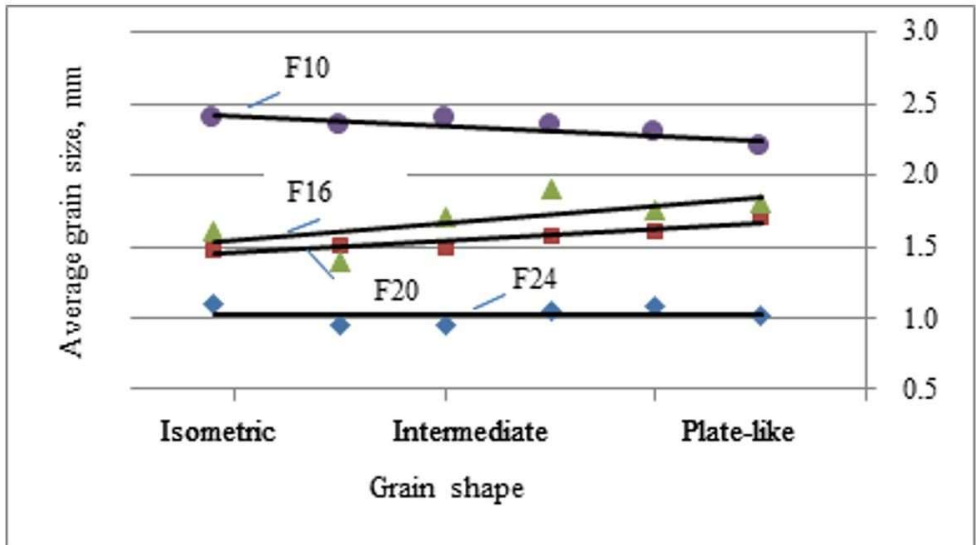

c) Average grain size

Fig. 5. Single-grain weight, width, and average size of diversiform grains

In addition to the direct influence of the abrasive grain shape on abrasive tool performance, the grain shape factor manifests itself in the course of grinding by means of a number of dependent such dependent parameters as elasticity, microhardness, grain mechanical strength, as well the abrasive tool structure and strength.

\section{Conclusions}

All this suggests that the grain shape is an essential feature that predetermines abrasive tool performance to a greater extent.

\section{References}

1. N.V. Baidakova, T.N. Orlova, International Conference on Industrial Engineering, ICIE 2017, 188 (2017)

2. N.V. Baidakova, T.N. Orlova, International Conference on Industrial Engineering, ICIE 2017, 194 (2017) 
3. V. M. Shumyacher, A. V. Slavin, S. A. Kryukov, 2nd International Conference on Industrial Engineering, ICIE 2016, 916 (2016)

4. A. V. Slavin, S. A. Kryukov, 2nd International Conference on Industrial Engineering, ICIE 2016, 911 (2016)

5. S. A. Kryukov, A.S. Kryukova, International Conference on Industrial Engineering, ICIE 2017, 200 (2017)

6. S. A. Kryukov, A.S. Kryukova, International Conference on Industrial Engineering, ICIE 2017, 204 (2017)

7. S. A. Kryukov, M.A. Tkach, International Conference on Industrial Engineering, ICIE 2017, 200 (2017)

8. H.N. Bauman, American Ceramic Society Bulletin, 10, 35 (1956)

9. G.A. Bird, Oxford: Science Publications, 350 (1994)

10. D.B. Hasselman, H.J. Amer, Ceram. Soc, 4, 215 (1969)

11. A. Kezdi, Handbuch der Bodenmechanik, 97 (1969)

12. W. Konig, E. Bottler INFOS, 91, 45 (1978)

13. W. Konig, W. Lorts CIRP, 24, 231 (1975)

14. T. Suto, T. Waida, Bulletin of Mechanical Engineering Laboratory, 8, 1 (1973)

15. J. Tobochnik, P.M. Chapin, J. Chem. Phys., 88, 58 (1988)

16. M. Moser, J. Peters, Annals of the CIRP, 1, 103 (1973)

17. Okamura Kenjiro Nakajima Toshkatsu, Wheel. Mem. Fac. Eng. - Kyoto Univ., 4, 490 (1969) 